\title{
In-situ soot particle sensing in an aero-engine exhaust plume
}

DOI:

10.1109/ICSENS.2013.6688442

Link to publication record in Manchester Research Explorer

\section{Citation for published version (APA):}

McCormick, D., Ozanyan, K. B., Black, J. D., \& Feng, Y. (2013). In-situ soot particle sensing in an aero-engine exhaust plume. In IEEE SENSORS 2013 - Proceedings/IEEE SENSORS - Proc. IEEE.

https://doi.org/10.1109//CSENS.2013.6688442

\section{Published in:}

IEEE SENSORS 2013 - Proceedings|IEEE SENSORS - Proc.

\section{Citing this paper}

Please note that where the full-text provided on Manchester Research Explorer is the Author Accepted Manuscript or Proof version this may differ from the final Published version. If citing, it is advised that you check and use the publisher's definitive version.

\section{General rights}

Copyright and moral rights for the publications made accessible in the Research Explorer are retained by the authors and/or other copyright owners and it is a condition of accessing publications that users recognise and abide by the legal requirements associated with these rights.

\section{Takedown policy}

If you believe that this document breaches copyright please refer to the University of Manchester's Takedown Procedures [http://man.ac.uk/04Y6Bo] or contact uml.scholarlycommunications@manchester.ac.uk providing relevant details, so we can investigate your claim.

\section{OPEN ACCESS}




\title{
In-Situ Soot Particle Sensing in an Aero-Engine Exhaust Plume
}

\author{
David McCormick, Krikor B. Ozanyan \\ School of Electrical and Electronic Engineering \\ The University of Manchester \\ Manchester, United Kingdom, M13 9PL
}

\author{
John D. Black \\ Strategic Research Centre \\ Rolls-Royce plc. \\ Derby, United Kingdom, DE24 8BJ
}

\author{
Yutong Feng \\ Optical Research Centre \\ The University of Southampton \\ Southampton, United Kingdom, SO17 1BJ
}

\begin{abstract}
This paper reports the use of a fiber-laser to produce spatially resolved images of the distribution of absorbing particles in the exhaust plume of a modified helicopter gas turbine engine. In-situ sensing of soot particles by LaserInduced Incandescence (LII) is demonstrated using fiber-lasers with higher power, longer pulse duration, and higher pulse repetition rates than conventional LII. The sensitivity of the method is illustrated by the detection of ambient absorbing particles prior to engine running. With a running engine images are obtained in 0.01s. The demonstration of LII using fiberlasers is a first step in the development of a new model for longpulsed LII.
\end{abstract}

\section{INTRODUCTION}

Accurate measurement of soot distributions in aero-engine exhaust plumes is of interest in aerospace engineering because of the need to develop engines with less environmental impact and capable of burning sustainable fuels which must be shown to meet certification requirements for engine emissions [1]. Current requirements for emissions certification necessitate measurements of the smoke number (SAESN). This method is an extractive sampling technique using a rake of probes positioned in the exhaust plume of a running engine. A volume of gas from the engine is passed through filter paper and the reflectance of the filter paper is measured to determine the SAESN [2].

In practice, extractive measurements of the smoke number are time consuming and expensive, requiring the engine to be held in constant running condition for approximately 5 minutes for each measurement. Furthermore, since modern engines are considerably cleaner than when the smoke number measurement was introduced in the 1960s the low levels of soot will often fail to register any significant change in reflectance of the filter paper, particularly at low engine power

This research is funded as part of the "FLITES: Fibre-Laser Imaging of gas Turbine Exhaust Species" project (EPSRC Ref. EP/J002151/1) conditions. This is exacerbated by modern synthetic and biofuels, which produce less smoke than conventional oil-derived fuels. The limitations of current extractive techniques illustrate the need to investigate methods for rapid, cost-effective, and non-intrusive methods for sensing and measurement of gas turbine soot particulates [3].

Laser-Induced Incandescence (LII) is a measurement method which uses a pulsed laser to heat rapidly absorbing soot particles to a very high temperature, typically around 4000K, where they emit visible light [4]. Detection of this emitted light permits the determination of some physical characteristics of the interacting soot, with the resulting LII signal shown to be approximately proportional to the soot volume fraction [5]. LII is an established technique for measurement of soot volume fraction in combustion applications [6]-[7] and has been applied to in-situ measurement of soot particle concentration in aero-engine exhaust plumes [8]-[10]. Advantages of LII over traditional extractive methods for in-plume soot particle measurement are the increased sensitivity, the non-intrusive nature removing the physical difficulty of sensing within a hot high velocity flow-field, and a reduction in measurement uncertainties associated with the use of sampling probes and transfer lines.

Conventional LII systems for in-situ soot particle sensing in aero-engine exhaust plumes have employed a Q-switched $\mathrm{Nd} / \mathrm{YAG}$ laser producing around $100 \mathrm{~mJ}$ laser pulses shorter than 10ns at a Pulse Repetition Rate (PRR) of the order of 10s Hz. The low power and short laser pulses limit the sensitivity whereas the low PRR limits the number of measurements obtainable in realistic engine test conditions. Fiber-lasers have been identified as a high power, high PRR source with the facility of variable pulse length and temporal pulse shape, which could address the limitations associated with conventional LII [11]. 


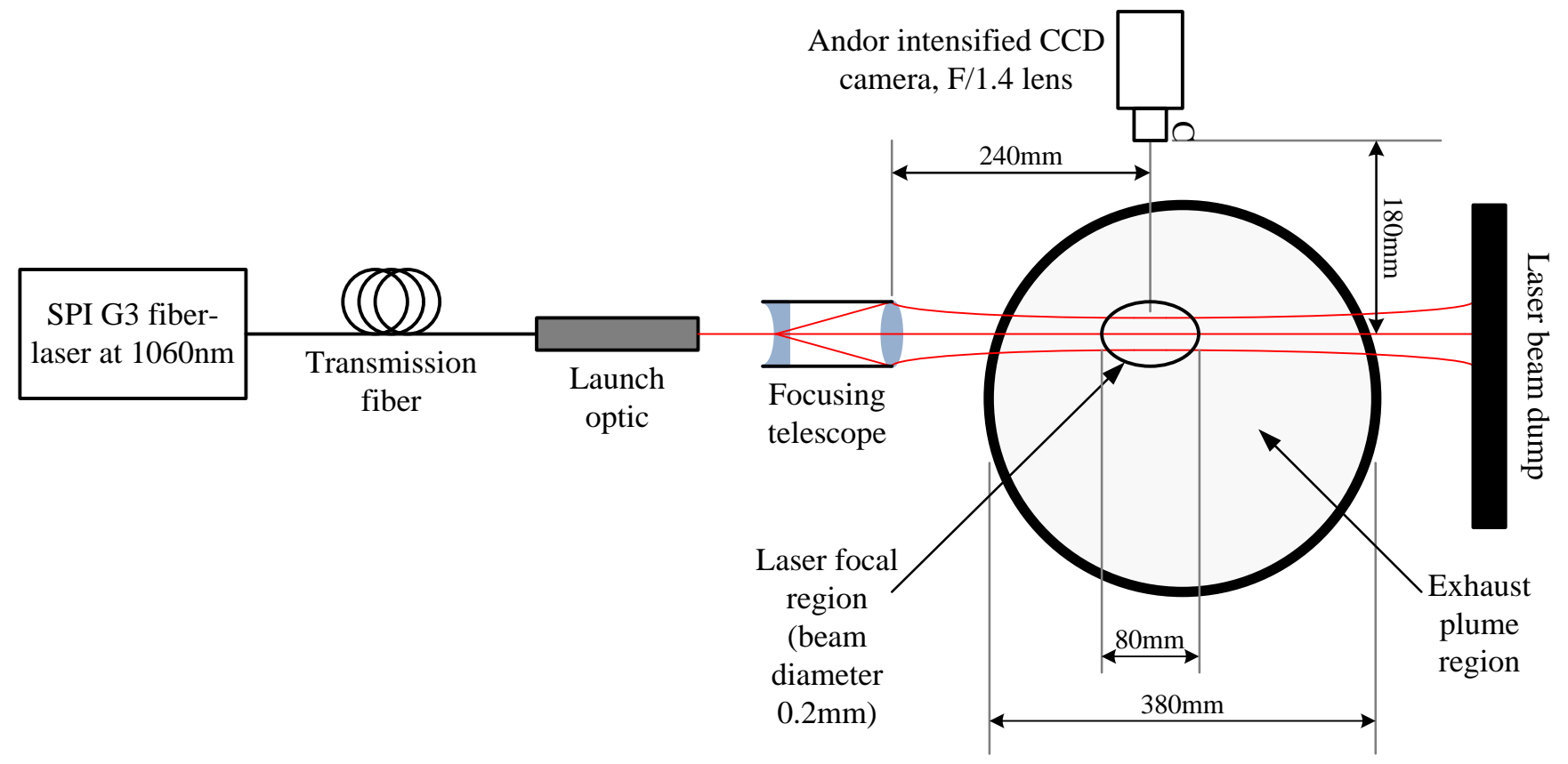

Figure 1. LII system for soot particle sensing experiments on a modified helicopter engine

\section{SoOt PARTICLE SENSING IN AN AERO-ENGINE EXHAUST PLUME}

\section{A. Experimental Engine}

This research focuses on investigating in-situ sensing of LII in the exhaust plume of a modified Rolls-Royce Gnome helicopter engine [12]. The Gnome is a direct-drive, singleshaft, 10-stage axial flow compressor turbine engine with a maximum power output of $1119 \mathrm{~kW}$ and overall pressure ratio of $8.4: 1$. The engine has been modified to remove the power turbine and shaft which makes the engine operate as a turbojet rather than a turboshaft helicopter engine. In normal engine running conditions, the modifications result in an increase in the temperature and velocity of the engine exhaust plume. A right-angle exhaust pipe with a central heat shield, which would surround the power turbine shaft, creates an inherently inhomogeneous exhaust plume which is ideally suited to experimental measurements of particulate distributions.

\section{B. LII System}

The schematic of the LII system for soot particle sensing experiments on the Rolls-Royce Gnome engine is shown in Figure 1. The source laser is a commercially available SPI G3 $1060 \mathrm{~nm}$ wavelength fiber-laser providing up to $30 \mathrm{~W} \mathrm{CW}$ equivalent power at $30 \mathrm{kHz}$ PRR. The laser output is delivered via a $2 \mathrm{~m}$ transmission fiber with $35 \mu \mathrm{m}$ core diameter to a collimating lens launch optic. Wide-field detection of LII is achieved using an Andor DH734 gated-intensified CCD camera with F/1.4 lens, orthogonally positioned at $180 \mathrm{~mm}$ from the laser beam. Via a PCI interface and a dedicated PCIcontroller the camera interfaces with a data acquisition workstation where raw data is recorded and time-averaged LII images are generated. All images are recorded with the camera operating in $\mathrm{CW}$ mode.
The laser is weakly focused in the exhaust plume using a focusing telescope located at the edge of the Gnome engine exhaust pipe. The focusing telescope is configured to create an $80 \mathrm{~mm}$ long laser focal region centered at $240 \mathrm{~mm}$ from the telescope. In this focal region the $1 / e^{2}$ beam diameter is constant at approximately $0.2 \mathrm{~mm}$ and the beam attenuation is linear because of low in-plume absorption at $1060 \mathrm{~nm}$. For reasons of optical access, the focal region is positioned offcenter, both longitudinally down the laser beam and axially across the exhaust plume. All results presented in this paper are of LII generated in this fixed focal region.

Figure 2 shows a trace of a 192ns duration laser pulse with sub 10ns rise time from the SPI fiber-laser. This laser pulse is much shorter than the created in-plume LII signal which builds up and decays in around $1 \mu \mathrm{s}$.

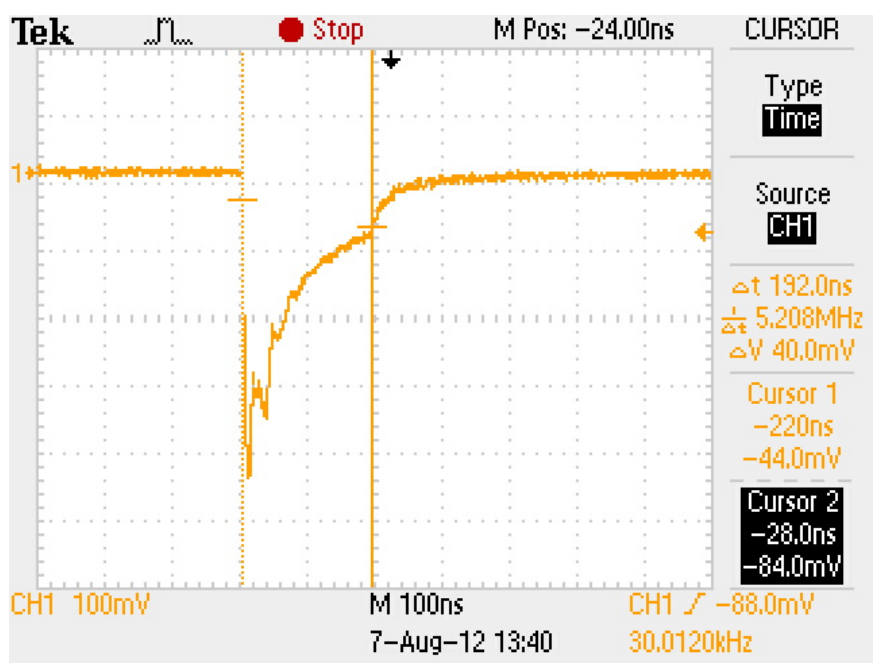

Figure 2. Trace of a 192ns duration pulse from the SPI fiber-laser showing a sub 10 ns rise time 


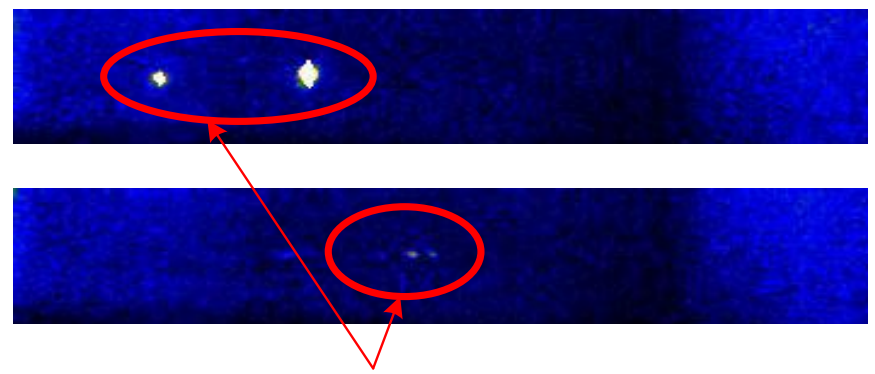

(a) Two instances of observed LII from ambient absorbing particles in laser beam. Images were acquired over a 1 second integration time

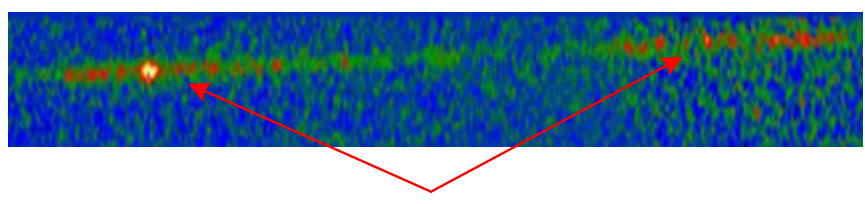

(b) Cumulative LII image taken over a 60 second period showing clusters of ambient absorbing particles along the laser beam path

Figure 3. Images of LII from ambient absorbing particles: LII in the laser focal region recorded over a 1 second integration time (a) and a cumulative image of LII recorded over a 60 second period. In all images the laser beam direction is from right to left

\section{IN-SITU SOOT PARTICLE SENSING RESUlts}

\section{A. Ambient Particle Sensing}

During the LII system set-up and calibration, LII of ambient absorbing particles in the laser focal region was observed with a laser power of $21 \mathrm{~W}$.

Several instances of ambient LII recorded over a 1 second integrated time show non-uniformly distributed absorbing particles, typically in the form of large agglomerates, located in the laser beam path (Figure 3a). A cumulative image of the ambient LII recorded over a 60 second period shows clusters of ambient absorbing particles at different locations along laser beam path (Figure 3b). This phenomenon has been observed previously [11] and may be due to ambient particles being trapped in the laser beam path forming high density aggregates of absorbing particles; however further investigation is required to verify this.

The observation of LII from ambient absorbing particles illustrates the sensitivity of using high power, long pulse, high PRR fiber-lasers for sensing of absorbing particles.

\section{B. In-plume Particle Sensing}

Results for the in-plume sensing of LII from soot particles are shown in Figure 4. Images for laser powers of $2.2 \mathrm{~W}$ (a) and $11 \mathrm{~W}$ (b) integrated over 1 second (30 000 pulses) are shown with the Gnome engine running at 19 475rpm. From the LII images the signal intensity along the laser beam is plotted with respect to the laser focal region center-line.
The recorded images demonstrate the feasibility of using high power, long pulse, high PRR fiber-lasers for in-situ sensing of LII from soot particles in the plume of a gas turbine engine. Higher laser power results in a more intense LII signal across the focal region. This is evident from the peak measured LII at the middle of the focal region, where an increase in laser power from $2.2 \mathrm{~W}$ to $11 \mathrm{~W}$ results in a 30 times enhancement of the LII signal, as well as broadening of the observed LII along the laser beam path.

LII images at laser powers greater than $11 \mathrm{~W}$ showed a lower LII signal at the center of the focal region; this was notably observable at laser powers above $20 \mathrm{~W}$ and can be attributed to soot particle vaporization caused by the higher laser fluence.

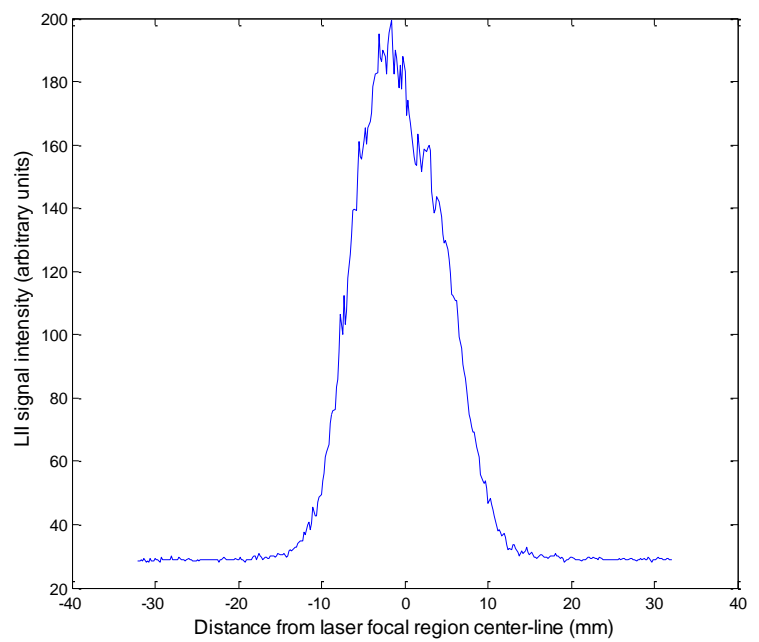

(a)

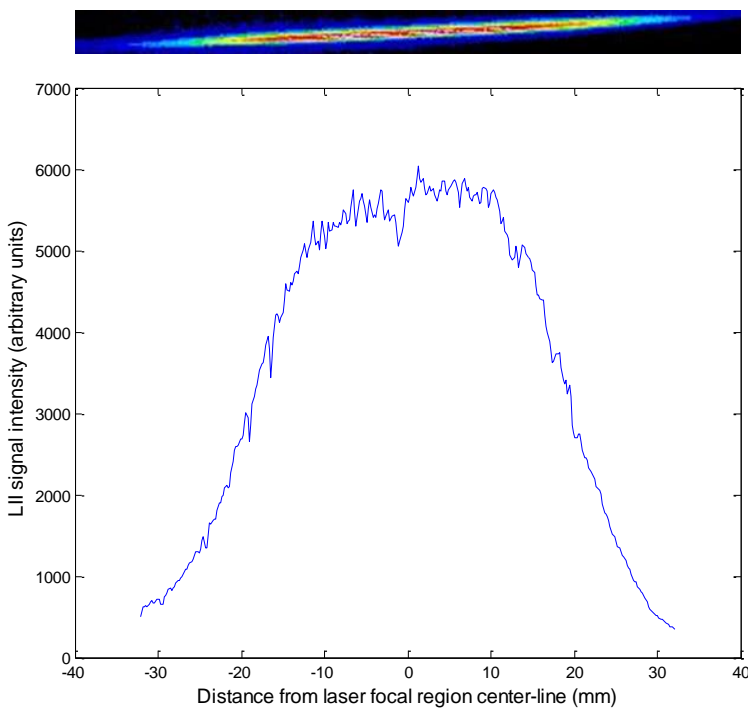

(b)

Figure 4. Image of in-plume LII integrated over 1 second (30 000 pulses) with plot of the LII profile with respect to the laser focal region center-line for $2.2 \mathrm{~W}$ (a) and $11 \mathrm{~W}$ (b) laser power 


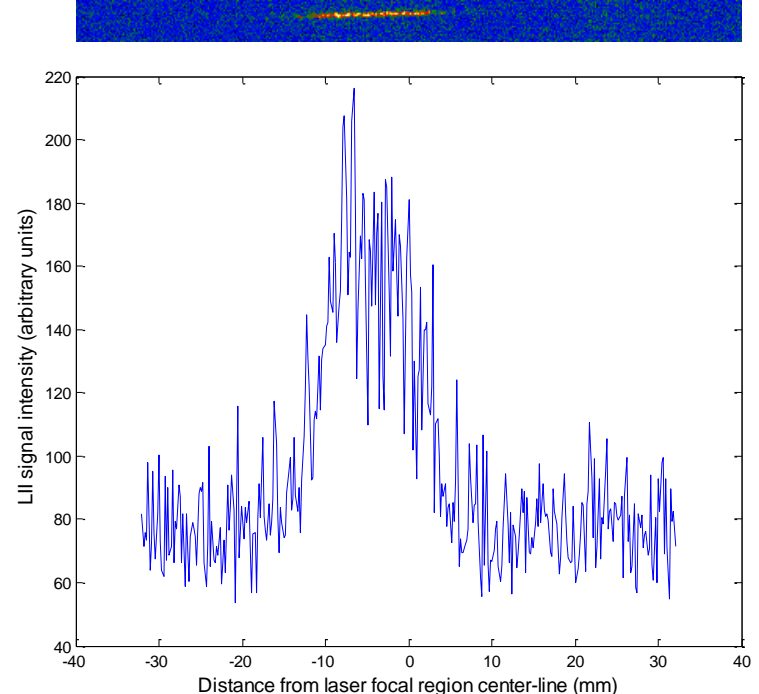

Figure 5. Image of in-plume LII integrated over 0.01 second (300 pulses) with plot of the LII profile with respect to the laser focal region center-line for $2.2 \mathrm{~W}$ laser power

To increase the data acquisition rate of the LII system the integration time for acquiring the images was reduced by altering the read out time from the Andor camera. Figure 5 shows the LII images and profile for a laser power of $2.2 \mathrm{~W}$ integrated over 0.01 seconds (300 pulses) with the Gnome engine running at $19475 \mathrm{rpm}$.

The general shape of the LII profile is similar to the 1 second integration profile (Figure 4a) with peak LII signal intensity of around 200, asymmetrically positioned around 5$10 \mathrm{~mm}$ to the left of the laser focal region center-line. The most obvious difference is the significant increase in noise on the data because of reduced signal sampling. Reducing the integration time further causes the noise to dominate the data. Further work will consider configuring the camera in gatedmode triggered from the laser pulse. This will permit acquisition of LII from individual laser pulses in an attempt to further reduce the integration time and hence increase the data acquisition rate.

\section{CONCLUSIONS}

In-situ sensing of LII from absorbing soot particles has been demonstrated using high power, long pulsed, high PRR fiber-lasers in the exhaust plume of a gas turbine engine. Images of ambient and in-plume LII generated from a 1060nm, 192ns pulse duration, 30kHz PRR fiber-laser have been presented. The reduction of the integration time has been considered and its impact on imaging performance and data acquisition rates has been discussed with further work identified.

The demonstration of LII using fiber-lasers is the first step in the development of new model for high power, long pulsed, high PRR LII for aero-engine combustion diagnostics. By scanning the laser beam, a 2-D image of soot distribution in the exhaust plume can be generated, giving access to information about the behavior of the combustor within the engine and the mixing of the core and bypass streams, which is currently unobtainable.

\section{REFERENCES}

[1] Conv. Int. Civil Aviation, Annex 16 Volume II, 2006 (9th Edition).

[2] Aircraft Gas Turbine Engine Exhaust Smoke Measurement, Aerospace Recommended Practice, SAE ARP1179 Rev. C, 1997.

[3] K. Schäfer et al., "Nonintrusive optical measurements of aircraft engine exhaust emissions and comparison with standard intrusive techniques," Appl. Opt., vol. 39, pp. 441-455, Jan 2000.

[4] L.A. Melton, "Soot diagnostics based on laser heating," Appl. Opt., vol. 23, pp. 2201-2207, Jul. 1984.

[5] H. Bladh et al., "On the dependence of the laser-induced incandescence (LII) signal on soot volume fraction for variations in particle size," Appl. Phys. B, vol. 90, pp. 109-125. Jan. 2008.

[6] R.L. Vander Wal and K.J. Weiland, "Laser-induced incandescence: development and characterization towards a measurement of soot volume fraction," Appl. Phys. B, vol. 59, pp. 445-452, Oct. 1994.

[7] D.R. Snelling et al., "Two-dimensional imaging of soot volume fraction in laminar diffusion flames," Appl. Opt., vol. 38, pp. 24782485, Apr. 1999.

[8] J.D. Black et al., "In-situ laser-induced incandescence of soot in large civil aero-engine exhausts," in 26th AIAA Aerodynamic Measurement Technology and Ground Testing Conf., Seattle, WA, 2008, pp. AIAA Paper 2008-4265.

[9] J. Delhay et al., "Soot volume fraction measurement in aero-engine exhausts using extinction-calibrated backward laser-induced incandescence," Appl. Phys. B: Laser and Optics, vol. 95, pp. 825-838, May 2009.

[10] J. D. Black and M. P. Johnson, "In-situ laser-induced incandescence of soot in an aero-engine exhaust: Comparison with certification style measurements," Aerosp. Sci. Technol., vol. 14, pp. 329-327, Feb. 2010.

[11] J.D. Black, "Fiber lasers as a source for laser-induced incandescence in practical applications", in Laser Applications to Chemical, Security and Environmental Analysis Conf., San Diego, California, 2010, pp. Paper LWB5.

[12] Flight International, "Turbine Engines of the World" in British European Aerospace/Preview of 1973, London: IPC Business Press Ltd, 1973, pp.36. 